\title{
El rol de los profesionales humanitarios frente al desplazamiento forzado
}

Raúl Gualtruzzi | Asociación de Voluntarios para el Servicio Internacional (AVSI), Brasil

Últimamente la mayoría de los artículos académicos que se escriben sobre la situación de los refugiados en el mundo y el drama del desplazamiento forzado comienzan repasando las cifras que anualmente publica el Alto Comisionado de las Naciones Unidas para los Refugiados (ACNUR), en un intento de dimensionar el drama de la crisis y redoblar los esfuerzos para que los gobiernos y nosotros mismos como sociedad, dejemos de mirar para otro lado y abordemos esta problemática con mayor empatía. No sólo acogiendo y protegiendo a las personas refugiadas, sino también, y aún mucho más importante, atacar las causas que se esconden detrás del desplazamiento, tales como la guerra, el conflicto y la persecución, así como también el hambre, las profundas desigualdades y el cambio climático, una mezcla de factores que representan el combustible que muchas veces aviva la llama de la mayoría de los conflictos que se conocen.

En 2020 el desplazamiento forzado batió nuevamente un récord histórico: 82,4 millones de personas forzosamente desplazadas, lo que equivale al $1 \%$ de la población mundial. De ese número, 26,4 millones son personas refugiadas, es decir, personas que buscaron seguridad y protección en otro país. Asimismo, un dato no menor, el $86 \%$ son acogidas en países en desarrollo, tales como Turquía, Colombia, Paquistán o Líbano (ACNUR, 2021).

Cuando mencionamos este último dato no deja de sorprender, pues choca y desmitifica la imagen que comúnmente nos llega de los medios cuando se habla de crisis de refugiados en Europa, por ejemplo, cómo podemos observar en el reciente conflicto en la frontera de Polonia y Bielorrusia, o cuando asistíamos atónitos la construcción de un mega muro que Estados Unidos erigía en la frontera con México para impedir el acceso de migrantes y refugiados. Sin embargo, pese al mito, las imágenes de pateras que se hunden intentando cruzar el mediterráneo para llegar a Europa, las devoluciones "en caliente" o mismo la persecución legal a las organizaciones humanitarias que intentan rescatar a estas personas de morir ahogadas (cuando consiguen zarpar sus barcos de rescate si es que no lo impiden las mismas autoridades), sí son reales y dejan en evidencia las constantes y flagrantes violaciones a las normas más elementales que la comunidad internacional elaboró en materia de Derechos Humanos.

Párrafo aparte merece observar como en los últimos tiempos ha ido variando la dinámica de los conflictos armados que actualmente se conocen. Guerras de nunca acabar, con potencias que manejan recursos inagotables para hacer la guerra en los países afectados, que se convierten en teatro de operaciones y rehenes de dinámicas geopolíticas que en definitiva terminan exponiendo a la población civil a las peores atrocidades. Países que quedan en ruinas, absolutamente devastados y, lo que es más difícil, sus entramados sociales profundamente quebrados. Lo vemos en Siria, un país que ya lleva una década sumido en la guerra, en Sudán del Sur, Ucrania, Libia, y una larga lista de etcéteras.

Cómo citar este artículo: Gualtruzzi, R. (2021). El rol de los profesionales humanitarios frente al desplazamiento forzado. Revista Electrónica de Derecho Internacional Contemporáneo, 4(4), 024. https://doi.org/10.24215/2618303Xe024 
Aún incluso más cerca, en nuestra región podemos observar la violencia y el conflicto por pandillas en los países del triángulo norte de Centroamérica, el conflicto armado de Colombia, que ya lleva décadas y cuyas cicatrices aún no cierran, y en Venezuela, país donde la violencia y las graves violaciones a los Derechos Humanos, sumado a una crisis humanitaria sin precedentes, ya ha expulsado de su país a más de 6 millones de personas. ${ }^{1}$

Esta realidad necesitará, más que nunca, de profesionales del derecho dispuestos a abogar por la causa de los refugiados y trabajar en su defensa y acceso a derechos. Claro que desenvolverse en el ámbito humanitario no es una tarea fácil, aunque el sentido de servicio que puede dársele a nuestra profesión les aseguro que es absolutamente gratificante.

En efecto, muchos de los profesionales del Derecho y de otras áreas que de una u otra forma se involucran en el trabajo con personas migrantes y refugiadas lo hacen dentro del amplio abanico que envuelve el concepto de "protección internacional", la cual puede definirse en términos sencillos como "la ayuda que se ofrece a una persona que está fuera de su país y no puede regresar allí porque su vida corre peligro", la que no sólo está dirigida a personas refugiadas, solicitantes de asilo y apátridas, sino también a "personas que no son refugiadas, pero que igual necesitan de protección internacional, como aquéllas que cruzan una frontera internacional debido a un desastre natural" (ACNUR, 2018). ${ }^{2}$ Así, bajo esta definición podemos englobar a todas las acciones destinadas a obtener el respeto total de los derechos de las personas, algo que naturalmente toma especial relevancia en situaciones de conflictos armados, violencia generalizada, desplazamiento forzado o mismo desastres, donde la población se encuentra con mayor vulnerabilidad, es expuesta a todo tipo de riesgos y muchas veces acceder a sus derechos más básicos representa un verdadero escollo.

Esto último resulta muy importante, porque cuando hablamos de desplazamiento forzado y, de movilidad humana en general, no debemos dejar de atender lo que Daniel Briggs (2020) califica como negocios de la miseria, aquéllos que se valen de la destrucción y desesperación de las personas, y entre los que se inscriben la trata de personas, el tráfico ilícito de migrantes, la explotación sexual y laboral, el tráfico de armas, los intereses detrás de cada guerra y una lista de nunca acabar.

Recuerdo mi primera experiencia, allá por el año 2015 en Roma mientras realizaba una pasantía profesional y que termina con una maestría en Relaciones Internacionales. La organización se llamaba Ciudadanos del Mundo $^{3}$ y su principal misión era precisamente brindar asistencia y asesoramiento a migrantes y refugiados que buscaban comenzar de nuevo en el viejo continente. Fue mi primera misión con personas en situación de vulnerabilidad extrema y un camino de ida que me permitió encontrar el sentido a mi carrera y resignificó profundamente todo lo que había estudiado en mi carrera de Derecho.

Luego de ello, vendrían otras experiencias trabajando en barrios vulnerables de la ciudad de Buenos Aires, hasta que finalmente comencé a colaborar en ACNUR, como voluntario primero, y luego como oficial de elegibilidad asistiendo a la Comisión Nacional para los Refugiados en Argentina, cargo que desempeñé durante tres años. Allí tuve la oportunidad de conocer cientos de historias de personas que buscaban protección en nuestro país y solicitaban el reconocimiento de su condición de refugiadas. Para tener una idea, de acuerdo a las estadísticas oficiales, Argentina recibió entre 1985 y 2020 un total de 29.530 solicitudes del estatuto de refugiado. Entre las principales nacionalidades pueden encontrarse personas que vienen de Venezuela, Siria,

\footnotetext{
${ }^{1}$ Esta cifra representa la suma de refugiados, migrantes y solicitantes de asilo venezolanos reportados por los gobiernos anfitriones, de acuerdo a la R4V, Plataforma de Coordinación Interagencial para Refugiados y Migrantes de Venezuela. Puede consultarse más información en https://www.r4v.info/.

${ }^{2}$ Quienes deseen ampliar sobre éstos conceptos, se sugiere la siguiente lectura: Alto Comisionado de las Naciones Unidas para los Refugiados (ACNUR), Introducción a la Protección Internacional Protección de las personas de la competencia del ACNUR: Módulo autoformativo 1, 1 Agosto 200.Ddisponible en: https://www.refworld.org.es/docid/4714bd082.html

${ }^{3}$ Para más información ver: https://www.associazionecittadinidelmondo.it/
} 
Colombia, Cuba y Haití, país que como sabemos ha sufrido enormes consecuencias producto de los recurrentes desastres que se sucedieron en 2010, 2016 y más recientemente, en agosto de 2021.

Recientemente tuve la oportunidad de viajar y servir por primera vez en el "terreno", en Pacaraima, ciudad brasileña que se encuentra en la frontera con Venezuela y principal puerta de acceso a Brasil, donde por estos días tiene lugar a mayor operación humanitaria con personas migrantes y refugiadas en todo el continente. La iniciativa conocida como "Operación Acogida", es liderada por el gobierno federal con el apoyo de distintas agencias del Sistema Naciones Unidas, organismos internacionales, organizaciones de la sociedad civil y componentes de las fuerzas armadas.

La operación tiene lugar principalmente en el estado de Roraima, y a partir de ella se brinda apoyo y asistencia a los flujos de personas desplazadas que ingresan desde Venezuela, a través de diferentes etapas que incluyen la recepción y el registro de las personas, la identificación, la inmunización sanitaria y la regularización migratoria sea a través del pedido de residencia o bien solicitando el reconocimiento de la condición de refugiados. Hasta junio de 2021, un total de 610 mil venezolanos habían ingresado a través de la frontera con Pacaraima, lo que representó un verdadero desafío a la hora de brindar una respuesta humanitaria acorde a las circunstancias. Todo ello se complementa con la acogida en los diferentes "abrigos", albergues instalados a lo largo del estado para alojar a aquellas personas que se encuentran en mayor estado de vulnerabilidad y sin medios para sustentarse. Sólo a modo de ejemplo, miles de personas son alojadas en los 5 abrigos de Pacaraima y en los 12 que operan en Boa Vista, ciudad capital del Estado de Roraima. Allí las personas encuentran no solo alojamiento, sino también protección, seguridad, alimentación, atención en salud y actividades sociales y educativas.

En definitiva, este breve recorrido a través de mi humilde experiencia personal y profesional, pretende mostrar y revalorizar un ámbito de desempeño de la profesión muchas veces desconocido pero que, así las cosas, resulta absolutamente necesario dar a conocer, puesto que el presente y, lamentablemente el futuro, requerirá de profesionales formados en valores empáticos hacia este tipo de problemáticas cada vez más frecuentes. El cambio climático, los conflictos y la violencia e inseguridad auguran un escenario en donde el desplazamiento forzado continuará siendo una realidad acuciante y cada vez más compleja, llena de desafíos que requerirán, como mencionaba, de profesionales formados en el ámbito humanitario y que vean a la profesión desde el servicio al prójimo y a los más vulnerables.

Decía un lema de ACNUR que buscaba concientizar sobre la realidad de las personas refugiadas, que esta realidad es una locura, pero aún más loco es no hacer nada por ayudar. Parafraseando el mensaje de la Agenda 2030, quizás abogar por un mundo más justo y equitativo en donde nadie quede atrás sea una de las claves para cambiarla. Pero lo que hacemos en el mientras tanto, hasta que ese anhelo, si fuera posible, comience a cobrar impacto es lo que puede definir el sentido que le damos a nuestra profesión y vocación, realizando nuestro pequeño aporte desde el ámbito en el que nos hemos formado o desde donde creamos que podemos hacer una diferencia.

\section{Referencias bibliográficas}

ACNUR (2021). Tendencias Globales, Desplazamiento Forzado em 2020. https://www.acnur.org/60cbddfd4.pdf

ACNUR (2005). Introducción a la Protección Internacional Protección de las personas de la competencia del ACNUR: Módulo autoformativo 1. https://www.refworld.org.es/do$\underline{\mathrm{cid} / 4714 \mathrm{bd} 082 . \mathrm{html}}$

ACNUR (junio 2018). Protección Internacional, la esperanza de millones de personas. https://eacnur.org/blog/proteccion-internacional-la-esperanza-de-millones-de-personastc alt45664n o pstn o pst/ 
Briggs, D. (2020). Climate Changed: Refugee Border Stories and the Business of Misery. Routledge. 